\title{
A RESTAURAÇÃO DO CRUZEIRO DO CONVENTO DE SÃO FRANCISCO DE OLINDA/PE
}

\author{
Hamilton Martins ${ }^{1}$, Vania Cavalcanti ${ }^{2}$ \\ 1 - IPHAN/Olinda/PE; 2 - Arquiteta e Urbanista, IPHAN \\ hamilton_martins@yahoo.com.br
}

\begin{abstract}
Resumo: Este artigo trata da restauração do Cruzeiro de São Francisco de Olinda, da preservação do patrimônio cultural, das técnicas e materiais tradicionais de construção e do saber-fazer tradicional do ofício da cantaria e técnicas para preservação. No Brasil, o Decreto no 3551/2000 estabeleceu quatro dimensões para registro dos bens do patrimônio imaterial: as celebrações, os saberes, as formas de expressão e os lugares expressivos, enquanto dimensões importantes ao estudo da cultura. Tais iniciativas rebatem-se diretamente sobre diferentes campos do saber, neste caso, à identificação, documentação e metodologia adotada na restauração do Cruzeiro, monumento integrante do conjunto arquitetônico tombado isoladamente pelo IPHAN desde 1938, a partir dos trabalhos de restauro realizados em 2016. De modo geral, essas condutas acompanham os procedimentos na área, metodologias de intervenção e preservação do saber-fazer dessa técnica milenar de construção. Sua durabilidade possibilitou a permanência e oportunidade de se poder, hoje, conhecer diversos monumentos edificados em pedra com trabalhos artísticos em cantaria. Para a conservação e o restauro de trabalhos em cantaria são necessários conhecimentos especiais quanto ao saber-fazer, cuja finalidade de estudo, nas concepções atuais, liga-se também à salvaguarda das técnicas construtivas tradicionais, assim como promover a permanência e conservação dos bens culturais. Nesse contexto, pretende-se mostrar os trabalhos realizados para restauração do Cruzeiro, identificação de danos, patologias e procedimentos para realização destes serviços em Pernambuco.
\end{abstract}

Palavras Chave: patrimônio, restauração, ofício de cantaria

Abstract: THE RESTORATION OF THE CRUISE FROM THE SÃO FRANCISCO MONASTERY OF OLINDA/PE. This article deals with the restoration of the Cross of St. Francis of Olinda, the preservation of cultural heritage, techniques and traditional building materials and traditional skills of the craft of stone masonry and techniques for preservation. In Brazil, Decree No. 3551/2000 established four dimensions for registration of property, intangible heritage: the celebrations, knowledge, forms of expression and significant places, while important dimensions to the study of culture. Such initiatives bounce directly on different fields of knowledge, in this case, the identification, documentation and methodology used in the restoration of Cruise, a member of the architectural monument set alone tumbled by IPHAN since 1938, from the restoration work carried out in 2016. Generally, these behaviors follow the procedures in the area, intervention methodologyes and preserve the know-how of this ancient construction techniques. Its durability allowed the permanence and opportunity to be able today to know several monuments built in stone with artistic stonework. For the conservation and restoration of stone work is required special knowledge about the know-how, the purpose of study, in the current conceptions, binds also to safe guarding the traditional construction techniques and to promote the permanence and conservation of cultural property. In this context, we intend to show the work done to restore Cruise, identification of damage, conditions and procedures for performing these services in Pernambuco.

Keywords: heritage, restoration, traditional craft

\section{INTRODUÇÃO}

O Convento de Nossa Senhora das Neves, localizado à Rua São Francisco, no 280, na cidade de Olinda, em Pernambuco, é o mais antigo Convento da Ordem Franciscana do Brasil e um dos bens protegidos pela nação que compõem a relação de testemunhos da cultura do nosso país. Está inscrito no Livro do Tombo de Belas Artes, Vol. I - Processo 143-T-38, folha no 33, Inscrição no 189, desde 22/07/1938. O conjunto foi tombado como Igreja e Convento de Nossa Senhora das Neves, capela, casa de oração e claustro dos Terceiros Franciscanos, inclusive o Adro, o Cruzeiro e toda a área da antiga cerca conventual. Segundo Germain Bazin (1958), no ano de 1583 foi concedido o Alvará de Doação das terras de Olinda à Congregação Franciscana para fundação do primeiro Convento da Ordem no Brasil.

O início da construção se deu em 1585, ano em que os franciscanos vieram morar no convento e construíram um seminário para recolhimento e educação dos índios e filhos de famílias importantes da época (GUIA DOS BENS TOMBADOS, 1980). Em
1585 os frades franciscanos chegaram a Olinda e receberam de Maria da Rosa, irmã da Ordem Terceira de São Francisco, doação da capela de Nossa Senhora das Neves assim como diversos terrenos em torno da mesma. O convento recebeu acréscimos até 1590, trabalhos realizados pelo Frei Custódio dos Anjos. Em 1631 a edificação foi incendiada durante a invasão holandesa ao Brasil e ficou abandonada.

Após a Restauração Pernambucana iniciaram-se as obras de reconstrução do convento, provavelmente, a partir da segunda metade do século XVII. Grande parte das obras de construção da azulejaria, cantaria e dos trabalhos artísticos foram realizados no decorrer do século XVII. O Convento possui um rico acervo de bens integrados em Estilo Dom João VI - Rococó - composto por forros, talhas, pinturas e altares, que configuram um dos mais admiráveis conjuntos artísticos do lugar (BAZIN, 1958). Em frente ao frontispício encontra-se uma 'cruz', possivelmente afixada no ano de $1700^{1}$,

\footnotetext{
Existe uma placa afixada próxima ao local com os dizeres: 'ESTE S. ESTAÇÃO REPRESENTA O LUGAR ONDE LERÃO A SENTENÇA DE JESUS CHRISTO E LHE POSER ̃̃O A CRUA A COSTA. ANNO DE 1700'. (BAZIN, 1958, p.129).
} 
vestígio de antiga via-sacra que se realizava na cidade e parte do ritual religioso católico. Outras adições foram executadas ao longo dos séculos XVIII e XIX, até adquirir a forma e o acervo que chegou aos dias de hoje, com o Adro e o Largo no qual se encontra o Cruzeiro (BAZIN, 1958). A edificação possui basicamente dois conjuntos: um pertence aos Terceiros, o outro, ao Convento. O Cruzeiro localizase em frente ao conjunto e faz parte do acervo tombado (Figura 1).

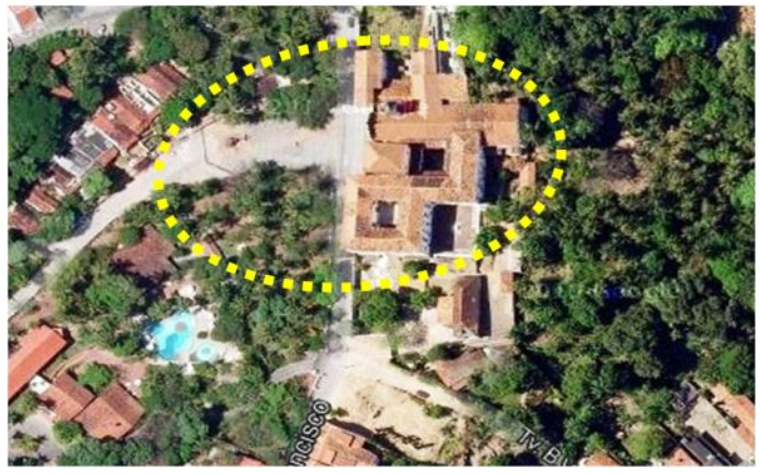

Figura 1. Situação do Convento de São Francisco/Olinda Fonte: https://www.google.com.br/maps/.Acesso em 18/12/2014

O conjunto formado pelo adro, pelo cruzeiro e pela torre recuada da fachada são especificidades dos conventos da Ordem Franciscana. Do cruzeiro é possível a apreensão da fachada principal da igreja. Encontra-se geralmente em posição simetricamente oposta ao frontispício. A partir da análise das figuras 2 e 3 é possível observar a relação de conjunto e de unidade existente entre estes elementos no Convento Franciscano em Pernambuco. O Cruzeiro de São Francisco em Olinda é parte integrante deste Conjunto Urbano e Arquitetônico. Construído em cantaria de pedra calcária, com formas artísticas peculiares, reentrâncias e saliências, com cruz implantada sobre estrutura octogonal e base retangular, destaca-se em meio à paisagem local, não apenas pela forma, mas pelo trabalho em cantaria, assim como pela importância simbólica enquanto local sagrado.

A técnica milenar de cantear legou à humanidade um patrimônio rico, empregado e difundido por inúmeras civilizações no mundo, chegando ao Brasil por intermédio dos portugueses na época da colonização. A durabilidade das construções e obras de arte em pedra possibilitaram a permanência e oportunidade de se poder, hoje, conhecer diversos monumentos edificados em pedra com trabalhos artísticos em cantaria.

A restauração e conservação deste conjunto em cantaria remetem a questões importantes no que se refere à metodologia e prática à preservação de monumentos em pedra, considerando-se a falta de conservação no qual se encontrava, os riscos de perdas em face da demolição da base de sustentação do conjunto, das patologias e danos a que estava exposto, sem receber limpeza nem conservação adequadas à cantaria trabalhada na técnica tradicional. De um modo geral, as condutas para restauração de cantaria acompanham procedimentos e metodologias de intervenção específicas, assim como se voltam também à preservação do saber-fazer dessa técnica milenar de construção. Para a conservação e o restauro de trabalhos em cantaria são necessários conhecimentos especiais quanto ao saber-fazer, que nas concepções atuais, liga-se também à salvaguarda da técnica construtiva tradicional, a fim de promover a permanência e conservação dos bens e dos saberes que já não se empregam nas construções da contemporaneidade.

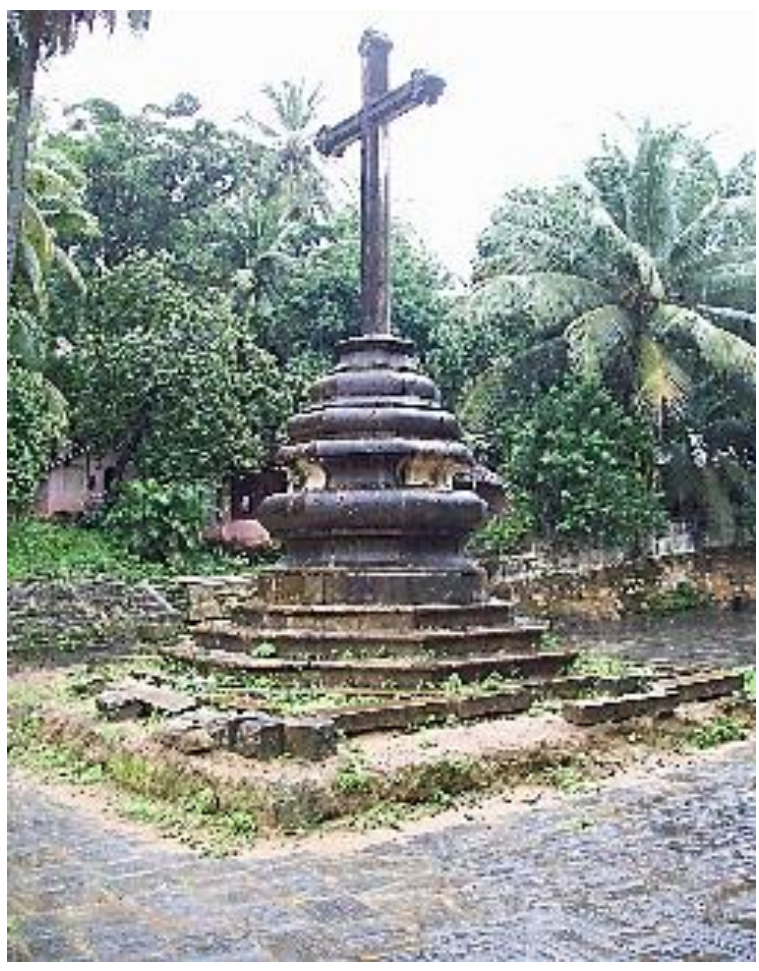

Figura 2. Situação atual do Cruzeiro em 2014 (Fotografia: Vania Cavalcanti)

Considerando-se estes argumentos, este artigo trata da restauração do Cruzeiro de São Francisco em Olinda, mostra a metodologia utilizada para os trabalhos realizados na restauração do Cruzeiro, identificação de danos, patologias e procedimentos para realização destes serviços, registrados enquanto fontes documentais imprescindíveis aos estudos no que se refere ao ofício da cantaria e técnicas para preservação. Para tal, este artigo está composto por 02 partes que compreendem a metolodologia empregada para realização do restauro, seguindo as etapas de diagnóstico, identificação de danos e patologias, assim como o processo de restauração realizado durante 04 meses. 


\section{DIAGNÓSTICO DO CRUZEIRO DE SÃO FRANCISCO}

O diagnóstico consiste no resultado do estudo realizado através do mapeamento dos danos e da análise do estado de conservação do bem estudado. No caso do Cruzeiro de São Francisco, foi produto do exame dos danos e patologias existentes no monumento, buscando-se também fazer uma relação dos mesmos associados aos agentes degradadores e suas causas. Para o diagnóstico o cruzeiro foi levantado e desenhado com o apoio de vasta documentação fotográfica. Após esta primeira etapa, os estudos tiveram continuidade com a identificação dos diferentes danos e a análise do Cruzeiro. Desse modo, o diagnóstico foi realizado em duas etapas: a primeira refere-se ao mapeamento de danos, a segunda, à análise do estado de conservação do Cruzeiro a receber intervenção para consolidação, conservação e restauro da cantaria com indicação dos tratamentos mais adequados a cada patologia ou dano.

\subsection{Mapeamento de Danos}

O mapeamento de danos é um procedimento que deve ser realizado para possibilitar a leitura da situação do estado de conservação dos elementos construtivos e estruturais e ornamentais que condicionam as possibilidades da intervenção, levando-se em consideração a correção, reparação e consolidação, limpeza, restauração e conservação, cujo objetivo final é obter a preservação e a salvaguarda do bem, conforme conceitos enunciados na Carta de Veneza e de Restauro (CURY, 2004) e de acordo com premissas gerais pertinentes e conhecidas dentro desse campo disciplinar e de trabalho.

'A metodologia a adotar inscreve-se no princípio dos processos patológicos e de danos, composto por uma fase de estudo inicial - anamnese - fase de estudo investigatórios - integrando as etapas de identificação dos sintomas (efeitos), dos agentes (ação) de causas (origem) e o tratamento proposto para cada caso. Deverão ser identificados e relatados os agentes físico-mecânicos que afetam as estruturas; os agentes físicos, químicos e biológicos que afetam os materiais; os agentes antrópicos de decorrem da ação humana de imperícia, negligência ou vandalismo e que afetam os materiais e as estruturas; e os agentes inerentes à construção que decorrem de erros de concepção ou execução em alguma fase da construção e que afetam materiais e estruturas. 0 mapeamento de danos deverá indicar todos os danos existentes no objeto deste projeto (Ver Item I deste Anexo) indicando-os em cada local pisos, alvenarias, cantarias, pinturas, coberta, estrutura da coberta, elementos de marcenaria e carpintaria e ferragens. Todos os ambientes deverão conter Fichas de Identificação de Danos com indicação dos agentes causadores e tratamento recomendado'. (www.iphan.gov.br).
A identificação dos danos do Cruzeiro foi feita a partir do levantamento das lesões observadas e registradas no local objeto da intervenção, relacionando danos e patologias aos seus agentes e causas (Portaria 420/2010 do IPHAN). Após realização do levantamento e tomando-se por base as vistorias técnicas realizadas ao local, foi possível identificar diversos danos e patologias de naturezas diversas e tratados em intervenções anteriores, com materiais diferentes. Foram identificadas patologias como: saturação de parafina de velas produzidas com gordura animal, acessas (e derretidas) em rituais religiosos; roubo de peças por vandalismo; presença de vegetação, manchas escuras (em cor negra e também avermelhadas) decorrentes do calor das chamas das velas e fumaça, da poeira local, intempéries. A continuidade da ação desses elementos possibilitou a alteração cromática da cantaria de forma irreversível.

Em virtude do abandono e da falta de conservação do local, o Cruzeiro é um dos elementos com maior desgaste, patologias, danos e perdas ao longo do tempo. Incluiu-se também o risco de perda de estabilidade porque a base que sustentava todo o conjunto, também estava desaparecendo por roubo de peças e pela ação das intempéries. Com base no estudo comparativo da documentação fotográfica produzida no decorrer das obras e do acompanhamento e monitoramento do local realizado pelo IPHAN, pode-se constatar que diversas pedras que faziam parte da base do cruzeiro foram perdidas. Algumas perdas são irreversíveis que só poderão ser compensadas pela substituição de peças e preenchimento de lacunas. Os principais danos têm por causa a ação do tempo e a falta de conservação.

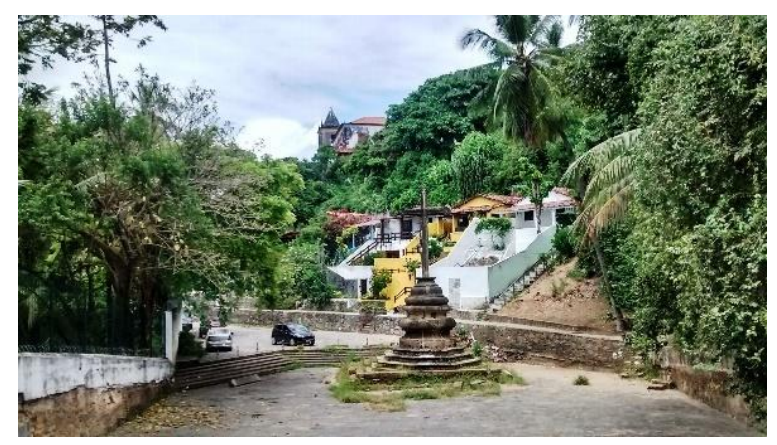

Figura 3. Situação atual do Adro e Largo do Cruzeiro em 2014

(Fotografia: Vania Cavalcanti)

Há perdas por vandalismo (as pedras do cruzeiro estavam sendo retiradas do local). Observou-se ainda presença de vegetação em diversos patamares do Cruzeiro. E ainda: saturação da cantaria por parafina, fissuras, vestígios de pintura branca de intervenção antiga, dentre outras, registradas no mapa de danos do projeto. A exposição da base do Cruzeiro trouxe também a perda de elementos em 
cantaria e a possibilidade de desestabilização do cruzeiro, uma vez que, as escavações realizadas no local para que o embasamento ficasse aparente, 0 que acarretou fragilidade da base, isto porque a cantaria foi assentada sobre o solo. A partir destas observações o mapa de danos foi elaborado identificando-se danos e patologias.

\subsection{Análise do Estado de Conservação}

A análise do estado de conservação dos materiais pontua e registra patologias e danos, lesões, perdas, lacunas, fissuras, degradações, deformações, descolamentos, etc.

É feito com relação a todos os aspectos do local estudado e objeto da intervenção, principalmente naqueles relativos às técnicas tradicionais da construção brasileira, como a cantaria do Cruzeiro do Convento de São Francisco de Olinda. No caso deste projeto, a análise decorre dos estudos e mapeamento de danos elaborados pelo Escritório Técnico de IPHAN em Olinda, que foi realizada após as conferências do levantamento existente no acervo técnico do IPHAN, do mapeamento de danos, identificação das patologias do cruzeiro.

Todo o trabalho considerou também os estudos e informações acerca do local, documentação fotográfica e vistorias registradas, nos quais se encontram designados os serviços a serem realizados para o tratamento de conservação e restauro do cruzeiro. Foram observados diversos problemas na base cuja degradação é visível. Encontra-se em mau estado de conservação, fragmentados com perda de peças da base.

De um modo geral, no Largo no qual se encontra o Cruzeiro, encontra-se grande quantidade de lixo que é jogado no local cotidianamente. Em volta do Cruzeiro há dejetos humanos e de animais, além de oferendas que semanalmente são oferecidos às entidades espirituais por diferentes crenças religiosas. Nesse contexto, uma quantidade grande de velas são acessas nos patamares do cruzeiro sem proteção, diretamente sobre a cantaria. Imagens realizadas no decorrer dos estudos para levantamento cadastral e mapeamento de danos comprovaram estes dados. Desse modo, o Cruzeiro, para ser preservado precisou de tratamento em face ao estado de degradação a que chegou até o ano de 2016, ano em que os trabalhos tiveram início e foram concluídos.

\section{.3. PROJETO DE RESTAURAÇÃO DO CRUZEIRO}

O Projeto de Restauração do Cruzeiro é parte do projeto para Requalificação do Adro do Convento Franciscano de Olinda/PE foi planejado para atender ao objetivo principal da Ação 300 do $\mathrm{PAC} \mathrm{CH}$ para Olinda: a reintegração do Adro e Largo do Cruzeiro, reconhecendo-se a significação deste ambiente urbano-arquitetônico e a importância do mesmo para a sociedade, de um modo geral, para a Ordem Franciscana e à cidade de Olinda. A proposta foi realizada pelo Instituto do Patrimônio Histórico e Artístico Nacional - IPHAN | Escritório Técnico do IPHAN em Olinda/PE fundamentou-se na preocupação com a estabilidade estrutural da área e do Cruzeiro, com vista à salvaguarda dos bens, conforme dispõe a Carta de Veneza de 1964. A solução teve como premissas valorizar o Adro, o Largo e o Cruzeiro de acordo com alguns pontos balizadores, ou premissas.

A restauração foi executada por cantéis especialistas em restauração e execução de peças estruturais e ornamentais. Ofício que se inicia desde o momento da escolha e seleção das pedras na pedreira, ao corte, a elaboração de peça lisas, trabalhadas ou ornamentais. Seguindo-se ao laborioso trabalho de limpeza, lavagem, consolidação, substituição de elementos faltantes, dentre outros serviços conforme cada caso, patologia ou dano identificado. No caso do cruzeiro, a restauração foi realizada respeitando-se a configuração do passado. Trata-se de um conjunto único, portanto, entende-se a importância do mesmo para a cidade. Para tanto, os princípios e critérios de projeto foram para garantir a manutenção dos valores atribuídos ao Conjunto Franciscano, promover a melhoria do local com iluminação, instalação de mobiliário urbano, consolidação estrutural do lugar, reestruturação das instalações de drenagem e águas pluviais, dentre outras ações importantes para devolver o espaço reabilitado para a fruição da comunidade local, da cidade e visitantes.

Nesse sentido, também os procedimentos para conservação e restauro passam a ser um conjunto de intervenções a serem adotadas pautadas em princípios específicos à área visando à preservação do bem cultural como um todo, devolvendo este ambiente às pessoas, enquanto espaço de encontros, interação, de trocas, de práticas religiosas, culturais e de sociabilidades. $O$ projeto de restauração do cruzeiro está composto por um conjunto de ações necessárias para caracterizar e justificar a proposta, assinalando soluções, metodologia de execução e usos. Para melhor compreensão das ações propostas, foi elaborado um quadro com as patologias, os danos e o tratamento a ser empregado cada um deles contém as soluções, quer sejam para limpeza, reconstituição, remoção de vegetação, dentre outros.

Todos os trabalhos de limpeza, conservação e restauro do Cruzeiro foram feitos com a intenção de dar maior longevidade ao cruzeiro por ser um monumento de grande valor artístico. Sendo assim, 
a reconstituição dos alicerces com tijoleira e argamassa cal maturada, foi realizada com a finalidade de dar estabilidade e evitar as perdas de pedras canteadas, já ocorridas porque estavam assentadas diretamente sobre o solo. Guiados pelo mesmo objetivo de oferecer longevidade $\mathrm{e}$ resistência ao longo do tempo, foi realizado o procedimento da carbonatação com água dura, com a certeza de que assim, o cruzeiro ficará preservado para fruição das gerações do presente e do futuro.

\section{CONSIDERAÇÕES FINAIS}

O Cruzeiro foi restaurado e hoje se encontra protegido. Durante o decorrer dos trabalhos alguns desafios apareceram, como a construção da base, que se optou por utilizar tijolos artesanais para oferecer maior segurança e estabilidade à base em cantaria. Foram realizados diversos testes utilizandose polpa de papel com produtos diferentes para observação da opção mais compatível com a cantaria. As vegetações foram removidas primeiro aplicando-se herbicida e depois removendo-se a vegetação para não haver danos à cantaria. As lacunas foram tratadas de duas maneiras: algumas foram complementadas e outras, dependendo do estado da pedra, tiveram que ser substituídas por pedras novas, trabalhadas pelos cantéis. Ao final dos trabalhos, a parte superior foi protegida porque as obras no largo e no adro estão em andamento, o que poderia acarretar sujidades ao bem restaurado. Ao final da obra a proteção será retirada e o Cruzeiro, inserido no largo e ao adro do Convento de São Francisco encontra-se agora salvaguardado.

\section{REFEREÊNCIAS BIBLIOGRÁFICAS}

BAZIN, Germain. A Arquitetura Religiosa Barroca no Brasil. Volume II. (1958).

Cadernos Técnicos № 1. Coordenado e Organizado pelo GT/IPHAN - Programa Monumenta - MinC/BID/UNESCO. Brasília. Dezembro de 2000.

CURY, Isabelle (organizadora). Cartas Patrimoniais. 2a edição revista e aumentada. Rio de Janeiro. Edições do Patrimônio IPHAN. 2000.
GUIA DOS BENS TOMBADOS - Coordenação de Pesquisa de Maria Elisa Carrazzoni. Rio de Janeiro: Expressão e Cultura, 1980.

KLÜPPEL, Griselda P. \& SANTANA, Mariely C. de. Manual de Conservação Preventiva para Edificações. Brasília: MinC, GT IPHAN - Programa Monumenta|BID.

Manual de Orientação de Projetos. Prefeitura Municipal do Rio de Janeiro. Empresa Municipal de Informática

VASCONCELOS, Silvio de. Arquitetura no Brasil: Sistemas Construtivos. Série Patrimônio Cultural. Publicação № 2. 5ạ ed. revista. Revisão e notas Suzy P. de Melo. Belo Horizonte. SEPLAN-PR/IPHAN/UFMG/FUNDEP.1979.

\section{SITES CONSULTADOS}

www.iphan.gov.br

www.ceci-br.org

\section{LEGISLAÇÃO}

Decreto-Lei № 25, de 30 de novembro de 1937. Organiza a proteção do Patrimônio Histórico e Artístico Nacional.

\section{ARQUIVOS | ACERVOS E PARECERES}

Acervo Técnico da Biblioteca Almeida Cunha - IPHAN/PE - Recife;

Acervo Técnico do Arquivo Geral - IPHAN/PE - Recife;

Acervo do Escritório Técnico do IPHAN/PE - Olinda:

3.1-Documentos, Relatórios Técnicos, Imagens e Pareceres;

3.2-Peças Gráficas Levantamento realizado no ano de 2011 pela empresa Grau - Grupo de Arquitetura e Urbanismo denominadas;

3.3-Parecer sobre a Cantaria do Convento de São Francisco (Hamilton Martins); Parecer de Arqueologia do IPHAN (Lívia Oliveira).

4. Trabalhos sobre o Convento de São Francisco apresentados em Seminários em Power Point de Fábio Cavalcanti e Carmen Muraro - Arquitetos do Instituto do PatrimônioHistórico e Artístico Nacional - IPHAN.

Contribuição ao 1‥ Simpósio Brasileiro de Caracterização e Conservação da Pedra 14 a 16 de dezembro de 2016, Congonhas - MG

Nota:

É de responsabilidade da comissão editorial do Simpósio a revisão gramatical, ortográfica, de citações e referências bibliográficas. As normas de submissão podem se diferenciar das desta revista. 